\title{
Quantification of acute myocardial injury in STEMI patients post revascularization at 3Tesla. Comparison of T1-mapping, late gadolinium and edema imaging
}

\author{
Dall'Armellina Erica*, Stefan K Piechnik, Vanessa M Ferreira, Theodoros D Karamitsos, Jane M Francis, \\ Matthew D Robson, Robin P Choudhury, Stefan Neubauer
}

From 2011 SCMR/Euro CMR Joint Scientific Sessions

Nice, France. 3-6 February 2011

\section{Objective}

To quantify myocardial injury in patients with acute STelevation myocardial infarcts (STEMI) by T1-mapping using Shortened Modified Look-Locker Inversion Recovery (ShMOLLI).

\section{Background}

Acute CMR imaging using late gadolinium (LGE) and T2-weighted imaging (T2W) is used to assess salvageable myocardium in STEMI patients post percutaneous coronary intervention (PCI) . However, current methods of assessing acute myocardial injury are being debated, and a more robust method would be desirable. T1-mapping quantitatively characterizes the myocardium without the need for comparing signal intensities against reference regions (ROI).

\section{Methods}

Seventeen STEMI patients (age $55 \pm 8$ years) underwent CMR imaging at 3T (TRIO, SIEMENS) 12-48 hours post PCI. Forty-seven matching short axis slices were obtained for cine-SSFP, T2prep-SSFP, LGE, and T1mapping (ShMOLLI). Segmentation was based on the AHA 17-segment model; volumetric fractions of injured myocardium per segment on LGE and T2W images were calculated using a signal intensity threshold 2SD above the mean intensity of a ROI in remote myocardium. Microvascular obstruction (MVO) identified on LGE images was manually segmented. For quantitative T1-mapping analyses, a threshold value of $1272 \mathrm{~ms}(10 \%$

\footnotetext{
OCMR, University of Oxford, Oxford, UK
}

above control T1s of $1156 \pm 67$ at $3 \mathrm{~T}$ ) was used. Wall motion was scored as normal, hypokinetic and akinetic. $\mathrm{T} 1$ values were calculated for segments with varying \% LGE lesion and/or wall motion abnormalities (WMA) and for areas of MVO.

\section{Results}

All patients had positive findings on cine, LGE, T2W and T1-mapping. The regions of myocardial injury assessed by the four modalities co-localized visually. Out of the 282 segments analysed, 39 were rejected for artifacts and 37 were identified as showing MVO and, hence were analysed separately. There was moderate correlation between the segmental damaged fraction assessed by LGE and T2W $\left(\mathrm{r}^{2}=0.51\right)$ and by LGE and

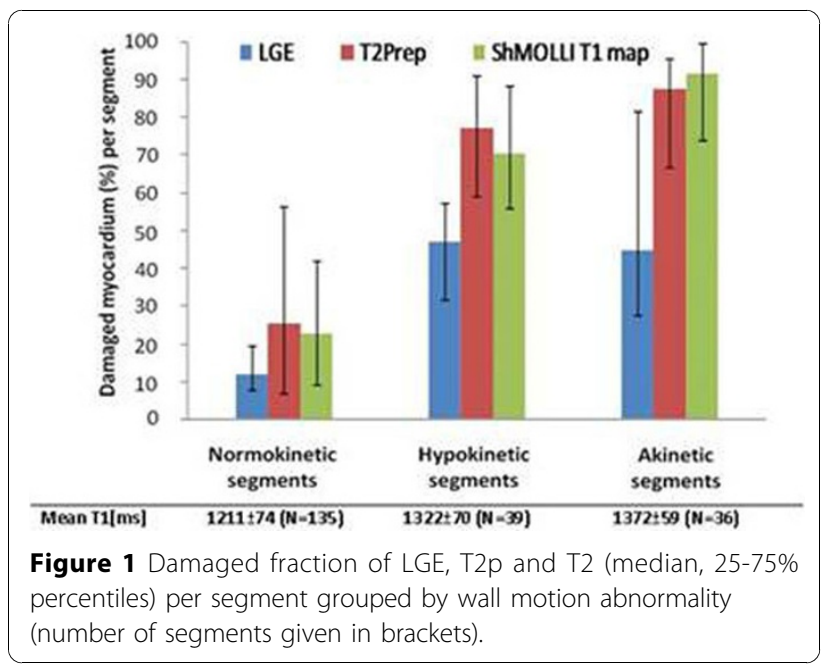

(c) 2011 Erica et al; licensee BioMed Central Ltd. This is an open access article distributed under the terms of the Creative Commons :HWed Central Attribution License (http://creativecommons.org/licenses/by/2.0), which permits unrestricted use, distribution, and reproduction in any medium, provided the original work is properly cited. 


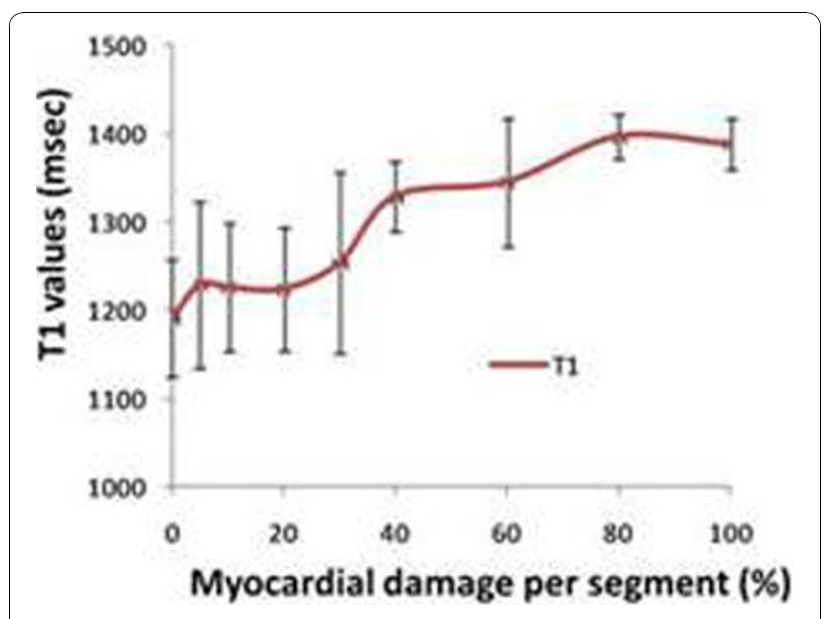

Figure 2 Segments with increasing damaged fraction assessed by LGE show longer T1-values.

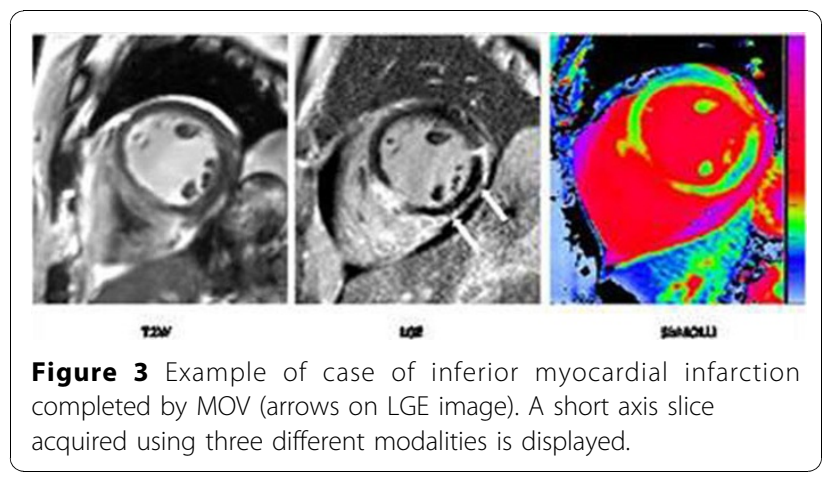

T1-maps $\left(r^{2}=0.48\right)$. A significant relationship was found between the volume of myocardial injury as assessed by T1-mapping, T2W and LGE, and the severity of WMA $(\mathrm{p}<0.01)$. (Fig.1). The T1-values increased with the severity of damage as assessed by LGE (Fig.2) reaching values significantly longer than the $\mathrm{T} 1 \mathrm{~s}$ in controls for segments with greater than 40\% damaged fraction (1356 $\pm 66 \mathrm{~ms}$ versus $1233 \pm 87 \mathrm{~ms}, \mathrm{p}<0.001)$. T1-values within areas of MVO were abnormal and included both long and short values $(1025-1380 \mathrm{~ms}$; mean $\pm \mathrm{SD}=1284 \pm 83)$ while $\mathrm{T} 1 \mathrm{~s}$ in the myocardium surrounding MVO areas reached values up to $1563 \mathrm{~ms}$ (Fig. 3).

\section{Conclusions}

ShMOLLI cardiac T1-mapping detects acutely injured myocardium in patients with STEMI and can identify segments with different degrees of damage as assessed by LGE.

Published: 2 February 2011
doi:10.1186/1532-429X-13-S1-P146

Cite this article as: Erica et al:: Quantification of acute myocardial injury in STEMI patients post revascularization at 3Tesla. Comparison of T1-

mapping, late gadolinium and edema imaging. Journal of Cardiovascular Magnetic Resonance 2011 13(Suppl 1):P146.
Submit your next manuscript to BioMed Central and take full advantage of:

- Convenient online submission

- Thorough peer review

- No space constraints or color figure charges

- Immediate publication on acceptance

- Inclusion in PubMed, CAS, Scopus and Google Scholar

- Research which is freely available for redistribution
C Biomed Central 